\title{
Portable autonomous solar power plant for individual use
}

\author{
Javoxir Toshov ${ }^{1}$, Elyor Saitov ${ }^{2}$ \\ ${ }^{1} \mathrm{DSc}$, Associate Professor, Dean of Energy Engineering faculty, Tashkent State Technical University, Uzbekistan \\ ${ }^{2} \mathrm{PhD}$, Associate Professor, Deputy Dean of Energy Engineering faculty, Tashkent State Technical University, Uzbekistan
}

\begin{abstract}
Development and design of low power mobile and inexpensive solar stations are important for farmers, individuals, geologists and trotters. The most important aspect is ensuring reliability of units in times of transportation, convenience and operational ease as well as minimum dimensions, low price. All the above will ensure large-scale implementation of solar stations in various applications and utilizations.
\end{abstract}

\section{Introduction}

Our modern society is constantly moving somewhere, and this movement, otherwise called "constant physical inactivity" - makes some sections of the population retire from society and its modern achievements. But, probably, nobody succeeds in completely retreating from all its features and achievements in the modern world, and therefore, although some minimal connection with it is necessary for everyone, even the most avid modern "aborigines" [1].

In this article we will consider mobile solar power plants based on solar batteries - through which, any of us, while away from home, is able to establish normal communication with family and friends, as well as provide our other, minimal energy needs.

The sun is a source of inexhaustible energy reserves, and the widespread use of this energy is one of the most urgent tasks for the Republic of Uzbekistan, which has significant solar energy resources. Other alternative sources of energy (ASE) are also significant.

The main supplier of solar electric energy are solar cells, the principle of which is based on the direct conversion of solar radiation energy directly into electrical energy. Solar cells generate energy at low operating costs and do not pollute the environment. Due to the increase in the cost of petroleum products, a sharp increase in demand for alternative energy sources is forecasted. The environmental and social effects of the use of solar power in remote and inaccessible areas should also be considered. The widespread use of alternative sources of energy will save natural resources, improve the ecology of the environment, reduce carbon dioxide emissions, improve living conditions of the population and stimulate the training of specialists in the field of alternative sources of energy [5-6].

\section{Main Body \\ 2.1 Theoretical analysis}

Calculations show that the use of alternative sources of energy in remote areas of the republic gives not only a social and environmental effect, but also a direct economic effect.

The aim of this work was the development of portable solar stations, providing lighting for at least 8 hours, charging mobile phones. At the same time, these stations should be convenient for transportation. In this case, it was necessary to accurately calculate the power of the solar flux, which would not only have to provide the necessary energy for the system for illumination at night with a duration of 8-10 hours, but also recharge the battery. However, the device should have been optimally sized for ease of transportation and placement [3]

In accordance with the requirements of [4], we developed a universal portable autonomous solar power plant for individual use, intended for the electrification of farms and summer cottages, as well as for use in remote and difficult to reach places where there is no traditional power supply.

The power of the solar panel is 20 watts. Inverter power maximum 300 watts. The effective output voltage of the inverter is $220 \mathrm{~V} \times$ with a frequency of 50 hertz. Battery capacity $14 \mathrm{~A} \times$ hour. The maximum duration of one TV and room lighting for 4 hours. The maximum duration of lighting a room for 20 hours. The equipment is placed in a case with a size of $15 \times 20 \times 30 \mathrm{~cm}^{3}$ in a protected version.

\subsection{Experimental part}

Currently, the world is actively developing the production of efficient solar cells for the development and commissioning of similar mini-solar stations [7-8].

However, it should be noted that the direct use of these sources is not possible due to a number of factors, since the energy generated by the photoelectric generator has a number of specific features:

- The non-stationary nature of energy production, which means that a system of energy storage (electrochemical battery) is needed.

- Typically, electrical energy is generated as a constant voltage in the range of 12 to 48 volts. 
At the same time, most household consumers (refrigerators, televisions, pumps, and others) require an alternating voltage of 50 hertz and a voltage of 220 volts.

To convert the DC voltage of solar stations to AC with the necessary characteristics, inverters are required [9-10].

Inverters for solar stations in their characteristics should differ significantly from the simplest inverters and uninterruptible power supplies, which are widely represented on the market. They should be distinguished by a high level of reliability, high overload capacity, built-in electronic protection systems [11-12]. Currently, "solar" inverters in the Republic of Uzbekistan are not produced by industry, and they have to be purchased for currency funds. There is also no production of some other nodes of solar and wind stations - battery charge controllers, supporting structures, there is a significant lag in this area. The development of the in-house production of such inverters is necessary for the successful implementation of small (up to $1 \mathrm{~kW}$ ) solar power plants for farmers and the population remote from industrial electrical networks. We developed at the Department of Digital Electronics and Microelectronics comprehensive solutions for creating a whole line of "solar" inverters with a capacity of up to $2 \mathrm{~kW}$ for various applications and installations of various capacities (charging cell phones, mobile solar power plants, etc.). The operational characteristics of the developed inverter with power up to $2 \mathrm{~kW}$ are given in the table.1.

\subsection{The results and discussion}

Mini solar stations with such inverters have been successfully tested in real conditions and have established themselves as reliable devices with a sufficiently long service life.

With the introduction of the developed inverter and the transition to its industrial production, it will be possible to refuse to purchase inverters for solar power plants abroad. This will significantly save foreign currency. Perhaps the widespread use of the developed inverter in all regions of Uzbekistan.
Table 1. Performance characteristics of the developed inverter

\begin{tabular}{|l|l|}
\hline Parameter Name & Parameter Value \\
\hline Rated Power & $2000 \mathrm{~W}$ \\
\hline $\begin{array}{l}\text { Maximum power (within } 3 \\
\text { minutes) }\end{array}$ & $2500 \mathrm{~W}$ \\
\hline $\begin{array}{l}\text { Short-term (up to 5 seconds) } \\
\text { overload capacity from the } \\
\text { nominal value }\end{array}$ & $50 \%$ \\
\hline DC input voltage & 21 to $30 \mathrm{~V}$ \\
\hline AC output voltage (50 Hz) & $220 \mathrm{~V}$ \\
\hline $\begin{array}{l}\text { Protection against short } \\
\text { circuit of loading 220B }\end{array}$ & Automatic switch 15A \\
\hline $\begin{array}{l}\text { The output voltage form } \\
\text { sinusoidal, with the } \\
\text { peaks limited by } \\
\text { protection device }\end{array}$ \\
\hline $\begin{array}{l}\text { Harmonic coefficient (at } \\
\text { rated power) }\end{array}$ & Not more than 5\% \\
\hline $\begin{array}{l}\text { Stability of the output } \\
\text { voltage (when the battery is } \\
\text { fully charged) and maximum } \\
\text { load }\end{array}$ & From +5 to $-10 \%$ \\
\hline Weight & not more than 20 kg \\
\hline Service life & Not less than 10 years \\
\hline Continuous Operation Time & Unlimited \\
\hline $\begin{array}{l}\text { Maintenance Need } \\
\text { Air Filter }\end{array}$ \\
\hline
\end{tabular}

A simplified diagram of the power part of the inverter is shown in Fig. 1.

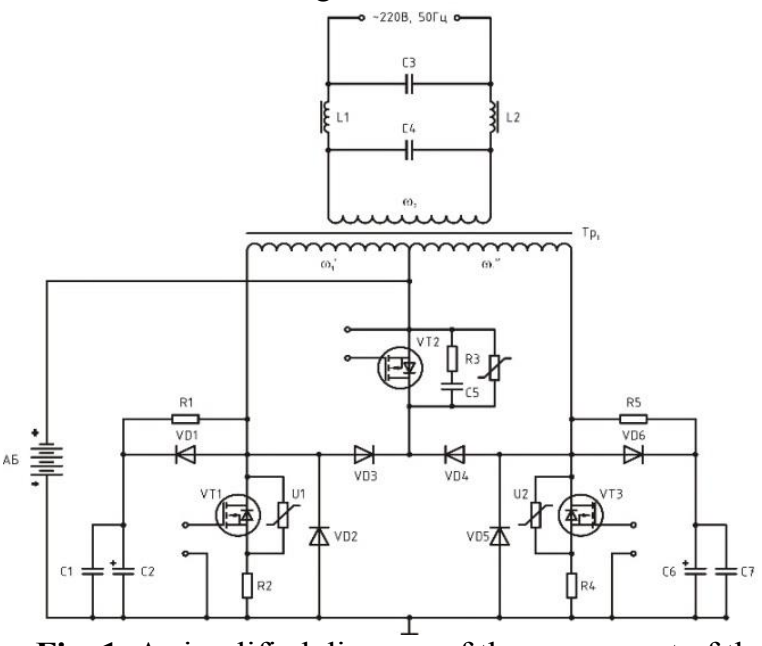

Fig. 1. A simplified diagram of the power part of the inverter.

The inverter power unit (Fig. 2) was made on the basis of $4 \mathrm{~mm}$ thick aluminum, on which insulated heat sink radiators of power transistors and diodes, as well as other elements of the power unit, were fixed.

The whole control unit circuit is divided into four parts according to the functional-node principle.

The following nodes were allocated:

- the microcontroller part, combining the 
microcontroller, the elements of the display of operating modes and controls,

- node high-speed protection and the formation of pulses of control power transistors,

- galvanic isolation node with three channels, - power node, forming the necessary parameters of the supply voltage.

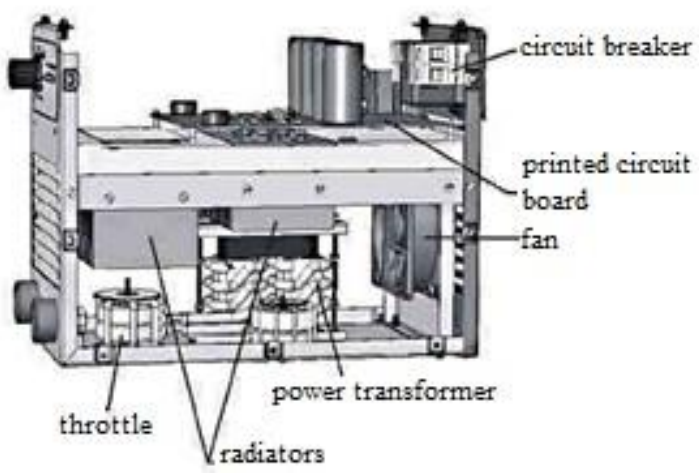

a)

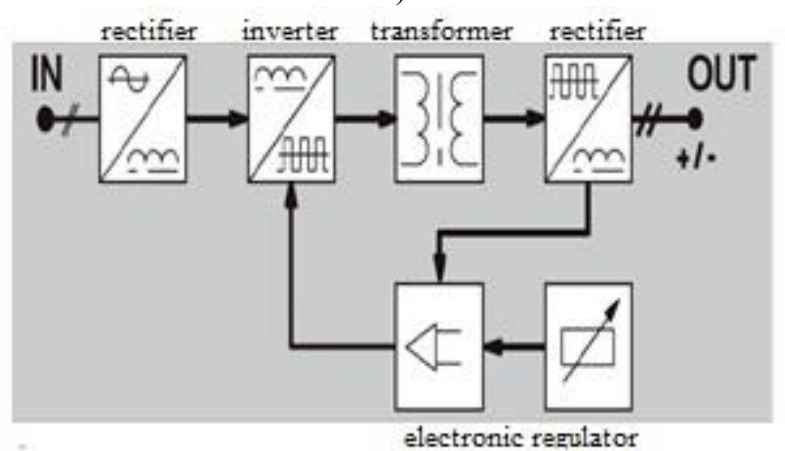

b)

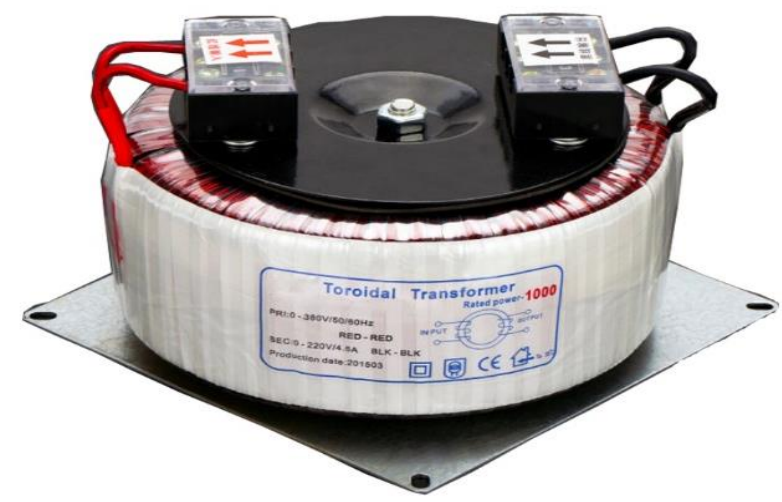

c)

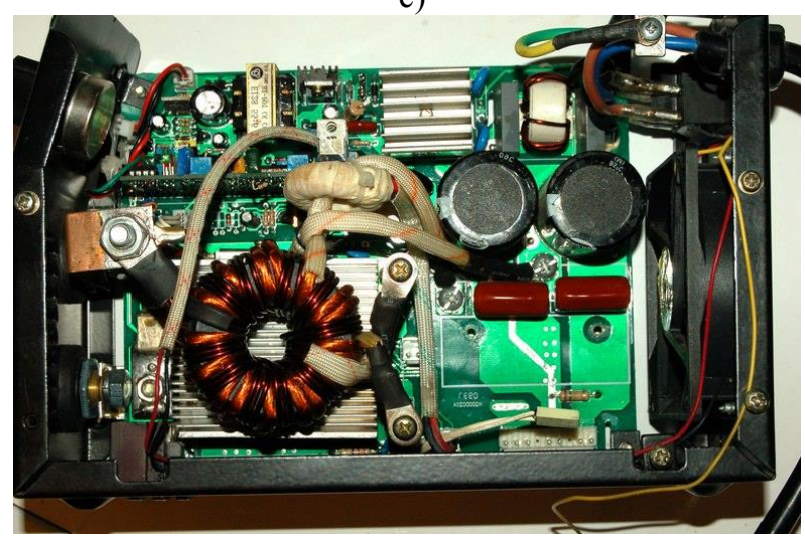

d)

Fig. 2. Power block inverter.
a) the power part design of inverter;
b) control and management scheme;
c) toroidal output transformer;
d) the appearance of the power part of inverter.

\section{Equations and mathematics}

As for the batteries, the rechargeable battery (assembled from finished batteries in parallel-serial connection to the desired voltage and capacity).

It should be noted here that the solar battery is a source of electric power, the properties of which are highly dependent on illumination. For the case of an ideal p-n junction $I=I_{S}\left(e^{\frac{U}{k T}}-1\right)-I_{\phi}$. The main dependencies follow from this formula: $U_{\text {o.c.c }} \sim \ln \Phi$, and $\mathrm{I}_{\text {sh.c.c }} \sim \Phi$, where $\Phi$ is the illumination of the solar battery (SB).

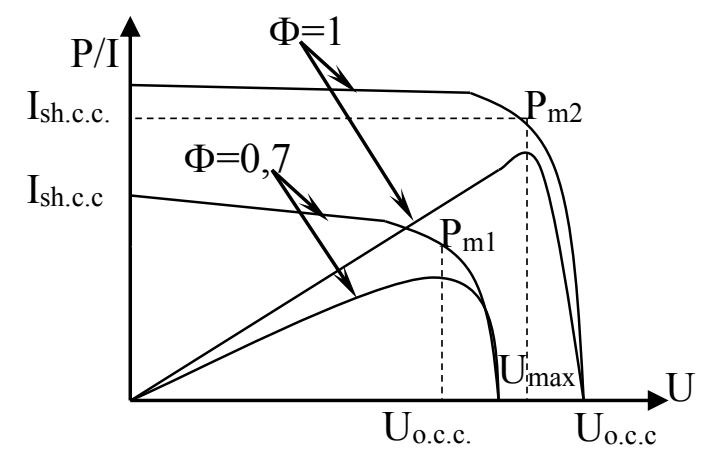

Fig. 3. Volt-ampere characteristic of the solar battery.

On (Fig. 3) the Volt-Ampere characteristic of the SB there is always a point at which its output power is maximum, but the position of this point changes (see the figure) from the illumination $\Phi$, which, in the case of a fixed SB installation, changes greatly during the day.

To increase the total efficiency. You can use a special charging regulator that optimizes the operating point of the SB.

\section{Conclusions}

Such a solar station provides continuous operation of one TV and lighting the room for 4 hours, and without a TV it illuminates the room and provides charging of cell phones for 20 hours. To ensure the operation of such stations, it is necessary to place a solar panel in the sun from 6 to 10 hours, depending on weather conditions. Our experiments have shown that the service life of such solar stations is at least 20 years, from time to time there is a need only to replace the batteries. Fig. 4. Below is the appearance and arrangement of such solar stations. 


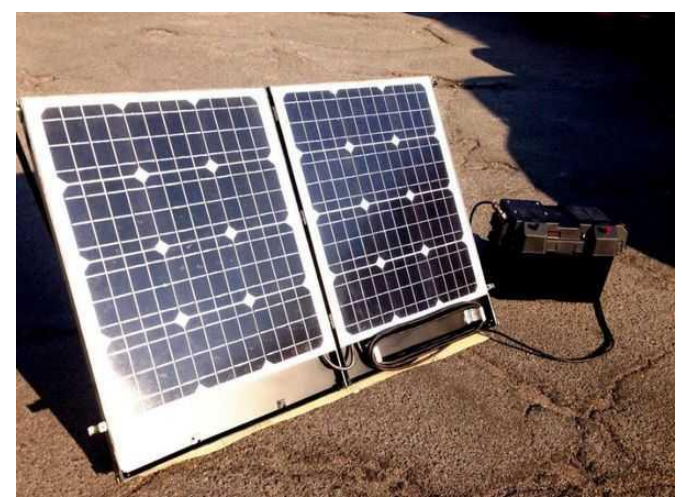

Fig. 4. General and appearance of the solar panel device.

This solar station is intended for individual use, as well as for use in remote and far apart places where there is no traditional power supply. Possible consumers of the products may be "Uzgydromet" Center JSC, Ministry of Agriculture, "Uzbekgeofizika" JSC, "Uzbekenergo" JSC, as well as organizations or individuals whose specific activity is to work in remote and hard-to-reach places where there is no traditional power supply.

Thanks to Academician M.K.Bahadirkhanov for discussing the results and valuable advice.

\section{References}

[1]. I.N. Sidorov, M.F. Biinatov, L.G. Shvedova. Reference: Inductive elements of electronic equipment. M .: Radio and Communication, 1992.

[2]. S.A. Eranosyan. Network power supplies with highfrequency converters. L .: Energoatomizdat, 1991.

[3]. Razevig V. D .. The use of P-CAD and PSpice programs for circuit simulation on a PC. Issue 3. Moscow: Radio and Communications, 1992.
[4]. N.F. Zikrillaev., S.A. Tachilin. E.B.Saitov. Efficient inverters for alternative energy sources. International scientific-practical conference "Problems of modern engineering" Andijan May 16-17, 2013.

[5]. E.B. Saitov., O. O. Ponomareva, H. Turaev. Solar radiation and wind in various regions. International scientific conference. Karshi April 15 - 17, 2016.

[6]. Zikrillaev N.F., Abdurakhmonov B.A., E.B. Saitov. The ability to create integrated photocells. International Scientific Conference "Innovations in Materials Science" (Tashkent-2014).

[7]. Kovalev F.I., Usachev V.A. The basics of power electronics. Power semiconductor devices. M.: Radio and Communication, 2012.

[8]. Saitov E. Study of Quantitative and Qualitative Characteristics of Nickel Clusters and Semiconductor Structures. International Journal of Advanced Research in Science, Engineering and Technology, Vol. 3, Issue 5, May 2016. pp. 1952-1956.

[9]. B. A. Abdurakhmanov, M. K. Bakhadirkhanov, K. S. Ayupov, H. M. Iliyev, E. B. Saitov, A. Mavlyanov, H. U. Kamalov. Formation of Clusters of Impurity Atoms of Nickel in Silicon and Controlling Their Parameters. Nanoscience and Nanotechnology, Vol. 4 No. 2, 2014. pp. 23-26.

[10]. Pavel Khavanov and Anatoly Chulenyov. Energyefficient solar power plants for autonomous heat supply in Russia. MATEC Web of Conferences 251, 03012 IPICSE-2018.

[11]. Paul Breeze. Solar Power Generation. ISBN 978-012-804004-1. Copyright (C) 2016 Elsevier Ltd. All rights reserved.

[12]. Tadashi Tanuma. Advances in Steam Turbines for Modern Power Plants. ISBN 978-0-08-100314-5. Published 2017. Copyright (C) 2017 Elsevier Ltd. All rights reserved. Imprint Woodhead Publishing No. of pages 568 . 